\title{
An Integrally-designed, Flexible Polysulfide Host for High-performance Lithium-sulfur Batteries with Stabilized \\ Lithium-metal Anode
}

Henghui Xu, Long Qie, and Arumugam Manthiram*

Materials Science and Engineering Program and Texas Materials Institute

The University of Texas at Austin, Austin, TX 78712, USA

\begin{abstract}
Fast capacity degradation and low sulfur loading hamper lithium-sulfur batteries from practical application. We present here a flexible and robust paper electrode consisting of carbon nanotubes (CNT) and activated carbon nanofibers (ACNF) loaded with $\mathrm{MnO}_{2}$ nanosheets to serve as an efficient sulfur host for $\mathrm{Li} /$ dissolved polysulfide batteries. This integrally-designed flexible host facilitates high sulfur loading, improves sulfur utilization, and suppresses effectively the parasitic shuttle. Accordingly, the Li/dissolved polysulfide cells with high sulfur loading exhibit a high-rate capacity of $780 \mathrm{mAh} \mathrm{g}^{-1}$ at $2 \mathrm{C}$ rate and a high capacity retention of $64 \%$ over 300 cycles, demonstrating great promise for practical applications of Li-S batteries. In addition, a stable lithium-metal anode resulting from the suppressed shuttle effect is also proved to contribute significantly to the promising cycling performance.
\end{abstract}

Keywords: lithium-sulfur batteries, flexible electrodes, polysulfide trapping, manganese dioxide

*Corresponding author. Tel: +1-512-471-1791; fax: +1-512-471-7681.

E-mail address: manth@austin.utexas.edu 


\section{Introduction}

Rapid developments in portable consumer electronics, electric vehicles, and grid energy storage accelerate the demand for high energy density Lithium-ion batteries (LIBs) at an affordable cost [1]. Lithium-sulfur batteries are receiving considerable attention in this regard because their high theoretical specific capacity $\left(1675 \mathrm{mAh} \mathrm{g}^{-1}\right)$ and energy density (2500 $\mathrm{Wh} \mathrm{kg}^{-1}$ ), far exceeding those of current LIBs based on insertion-compound cathodes and anodes [2]. In addition, sulfur has other favorable advantages: it is abundant, inexpensive, and environmentally benign [3]. Despite its promising prospects, several obstacles impede $\mathrm{Li}-\mathrm{S}$ batteries from commercial application, including (i) the insulating nature of both sulfur and its discharge products $\left(\mathrm{Li}_{2} \mathrm{~S} / \mathrm{Li}_{2} \mathrm{~S}_{2}\right)$, which limits the utilization of active material, (ii) the large volumetric change that occur upon cycling, which causes structural damage to the electrode, and (iii) the dissolution of polysulfide intermediates into the liquid electrolyte, which causes a severe shuttle effect and leads to fast capacity fade and lithium-metal corrosion [4].

Many strategies have been developed to improve the conductivity of the cathode and restrict the diffusion of soluble polysulfides. One of the most common approaches for improving the capacity and cyclability is encapsulating sulfur into a carbon matrix through melt-diffusion [5-9]. The carbon matrix provides an interconnected network for fast electron transfer, cavities to accommodate volumetric expansion during cycling, and a physical barrier to block the diffusion and loss of polysulfides $[10,11]$. However, the synthesis and processing involved could often be tedious and 
time-consuming. Carbon interlayers have been shown to act as an upper current collector for fast electron transport and provide a physical barrier to block the migration of polysulfides, but they introduce additional weight and thereby decrease the overall energy density [12-14]. In addition, the nonpolar nature of carbon dramatically weakens its ability to bind and confine the polar polysulfide species within the cathode during cycling [15].

Recently, compositing polar metal oxides with conductive carbon matrix has been extensively investigated to bond with polysulfide species [13, 16-22]. The combination of physical barrier and chemical binding of polysulfides greatly suppresses the polysulfide shuttle, and endows improved cycle stability. However, the sulfur utilization and rate performance are still low due to the intrinsically poor electrical conductivity of the metal oxides, especially at high sulfur loading ( $>2 \mathrm{mg}$ $\mathrm{cm}^{-2}$ ) [23-25]. Therefore, it is highly desirable, but still challenging, to achieve high sulfur utilization while effectively suppressing the polysulfide shuttle. Generally, the improved cyclability of Li-S batteries is ascribed to the suppressed polysulfides [26-29]. However, the key role of Li-metal anode hidden behind the suppressed polysulfide shuttle in contributing to the improved cycling stability has seldom been reported. Furthermore, the influence of polysulfide trapping on lithium-metal anode protection is also being largely neglected.

Herein, we present a flexible paper electrode composed of carbon nanotubes (CNT) and activated carbon nanofibers (ACNF) loaded with polar $\mathrm{MnO}_{2}$ nanosheets as a highly efficient sulfur host for Li/dissolved polysulfide batteries. The ACNFs are 
hollow, which provide a large reservoir for liquid polysulfides. The CNTs form a highly conductive network and firmly bind the electrode material together. The $\mathrm{MnO}_{2}$ nanosheets anchored to ACNF can chemically bind the polar lithium polysulfides and effectively suppress the shuttle effect. As a result, the Li/dissolved polysulfide cells exhibit high rate capacity and superior cycle stability at $0.5 \mathrm{C}$ rate over 300 cycles. In addition, we show that the suppressed polysulfide shuttle and the resulting stabilized lithium-metal anode contribute together to the improved cyclability.

\section{Experimental}

Fabrication of CNT/ACNF@MnO ${ }_{2}$ host for polysulfide catholyte: The ACNFs were prepared by activating CNFs with $\mathrm{CO}_{2}$ at a high temperature, as described previously [30]. The incorporation of $\mathrm{MnO}_{2}$ nanostructure on the surface of ACNF was achieved by immersing $\mathrm{ACNF}$ into a $\mathrm{KMnO}_{4}$ solution at $65^{\circ} \mathrm{C}[31,32]$. After $30 \mathrm{~min}$, the intermediate product $\left(\mathrm{ACNF} @ \mathrm{MnO}_{2}\right)$ was collected by vacuum filtration, followed by rinsing with water and isopropanol. Then, a pre-sonicated CNT solution in isopropanol, together with the obtained ACNF@ $\mathrm{MnO}_{2}$, was mixed, dispersed, and filtrated into a flexible CNT/ACNF@ $\mathrm{MnO}_{2}$ paper. Composite papers with higher mass could be obtained by simply increasing the thickness. In this work, different areal masses of $\sim 2,4$, and $6 \mathrm{mg} \mathrm{cm}{ }^{-2}$ were selected for CNT/ACNF@ $\mathrm{MnO}_{2}$ paper to host the polysulfides. For a comparison, CNT/ACNF and ACNF@ $\mathrm{MnO}_{2}$ were also prepared following a similar procedure described above.

Materials Characterization: The morphology and microstructure of the prepared materials were characterized by SEM (FEI Quanta 650) and TEM (JEOL 2010F). 
XRD patterns were collected on a Rigaku MiniFlex 600 instrument with $\mathrm{Cu} \mathrm{K} \alpha$ radiation $(\lambda=0.154056 \mathrm{~nm})$ between 10 and $80^{\circ}$. The cycled electrodes were washed with dimethoxyethane (DME) (Acros Organics) and sealed with Kapton film prior to the XRD test. XPS measurements were carried out on a Kratos spectrometer at room temperature with monochromatic $\mathrm{Al} \mathrm{K} \alpha(1486.6 \mathrm{eV})$ radiation. Raman spectra were recorded with a WITEC Alpha300 S micro Raman system under ambient conditions with a $488 \mathrm{~nm}$ laser. TGA was conducted on a TGA 4000 Thermogravimetric Analyzer (Perkin Elmer) under air flow to determine the $\mathrm{MnO}_{2}$ content.

Preparation of the base electrolyte and polysulfide catholyte: The base electrolyte was $1 \mathrm{M}$ lithium trifluoromethanesulfonate $\left(\mathrm{LiCF}_{3} \mathrm{SO}_{3}\right)$ and $0.2 \mathrm{M}$ lithium nitrate $\left(\mathrm{LiNO}_{3}\right)$ in a mixture of 1, 3-dioxolane (DOL) and dimethoxy ethane (DME) (1:1 v/v). The polysulfide catholyte was prepared by adding sublimed sulfur (99.5\%) and lithium sulfide $\left(\mathrm{Li}_{2} \mathrm{~S}, 99.9 \%\right)$ in the above base electrolyte to give $6 \mathrm{M}$ sulfur in the form of $\mathrm{Li}_{2} \mathrm{~S}_{6}(1 \mathrm{M})$ in the solution. The solution was then stirred and heated at $70{ }^{\circ} \mathrm{C}$ in an Ar-filled glove box for $48 \mathrm{~h}$ to produce a brownish-red $\mathrm{Li}_{2} \mathrm{~S}_{6}$ catholyte solution.

Electrochemical measurements: The Li/dissolved polysulfide batteries (2032-type coin cell) were assembled in an Ar-filled glove box. The CNT/ACNF@ $\mathrm{MnO}_{2}$ composite paper was pre-dried at $50^{\circ} \mathrm{C}$ under vacuum overnight before being cut into circular disks with an area of $1.13 \mathrm{~cm}^{-2}$ and areal mass of $\sim 2 \mathrm{mg} \mathrm{cm}^{-2}$. Subsequently, $\sim 14 \mu \mathrm{L}$ of polysulfide catholyte (1 $\left.\mathrm{M} \quad \mathrm{Li}_{2} \mathrm{~S}_{6}\right)$ was dropped onto the CNT/ACNF@ $\mathrm{MnO}_{2}$ paper electrode, corresponding to a sulfur content of $55 \mathrm{wt} \%$ and sulfur loading of $2.4 \mathrm{mg} \mathrm{cm}^{-2}$ in the entire free-standing cathode. For the higher 
sulfur loadings of 4.8 and $7.2 \mathrm{mg} \mathrm{cm}{ }^{-2}, \sim 28$ and $42 \mu \mathrm{L}$ of $\mathrm{Li}_{2} \mathrm{~S}_{6}$ solution was added respectively. Before placing the Celgard 2500 separator on top of the electrode, the electrode was allowed to stand for a while to ensure the full absorption of polysulfides. In sequence, the base electrolyte $(50 \mu \mathrm{L})$, lithium-metal anode, and nickel foam were added. The assembled cells were galvanostatically charged and discharged with an Arbin battery test station with a cut-off potential of $1.8-2.8 \mathrm{~V}$. The capacities were calculated based on the mass of sulfur in the catholyte. CV curves were recorded on a potentiostat (VoltaLab PGZ 402) at various scan rates of $0.1-0.5 \mathrm{mV} \mathrm{s}^{-1}$. Electrochemical impedance spectroscopy (EIS) data were collected before and after cycling with an impedance analyzer (Solartron 1260A) in the frequency range of 100 $\mathrm{kHz}$ to $10 \mathrm{mHz}$. For the symmetrical cell, two cycled Li-S cells were first disassembled and then the two Li electrodes were assembled in a symmetrical coin cell (2032-Type) in the glove box.

\section{Results and Discussion}

The flexible CNT/ACNF@ $\mathrm{MnO}_{2}$ paper electrode was fabricated through a facile vacuum filtration method (Figure 1). In brief, $\mathrm{MnO}_{2}$ nanosheets were first grown on to the ACNF via a bath deposition, and then the ACNF@ $\mathrm{MnO}_{2}$ composite and $\mathrm{CNT}$ were vacuum-filtrated into a hybrid film of CNT/ACNF@ $\mathrm{MnO}_{2}$. For a comparison, CNT/ACNF film was also prepared without $\mathrm{MnO}_{2}$ deposition. In the CNT/ACNF@ $\mathrm{MnO}_{2}$ host, liquid polysulfides can be uniformly distributed and trapped by the strong surface bonding with $\mathrm{MnO}_{2}$ nanosheets. Trace amounts of lithium polysulfides diffused out of the cathode, and $\mathrm{LiNO}_{3}$ was used as an electrolyte 
additive to facilitate the formation of a uniform passivation layer on the lithium-foil anode and prevent $\mathrm{Li}$ corrosion and electrolyte depletion [33, 34]. Without the assistance of $\mathrm{MnO}_{2}$, the CNT/ACNF host cannot effectively block polysulfides from migrating to the anode, which leads to the formation of a thick passivation layer on the corroded Li metal.

ACNF possesses a smooth surface, a diameter of $\sim 100 \mathrm{~nm}$, and a length of up to several micrometers. The hollow structure provides an ideal reservoir to accommodate polysulfides (Figure S1). Together with CNT, a hybrid CNT/ACNF membrane was prepared with vacuum-filtration (Figure S2). Scanning electron microscopy (SEM) images (Figure 2 a and b) show that the ACNF and CNT are well intertwined. The entangled network facilitates electron transfer and provides large interspaces to accommodate diverse materials, including the active materials. $\mathrm{MnO}_{2}$ covers the entire surface of the ACNF, and the CNT/ACNF@ $\mathrm{MnO}_{2}$ paper is formed after immersing CNT/ACNF in $\mathrm{KMnO}_{4}$ solution for only 30 min, making the ACNF surface much rougher (Figure $2 \mathrm{c}$ and $\mathrm{d}$ ). The transmission electron microscopy (TEM) images reveal more clearly the $\mathrm{MnO}_{2}$ distribution and microstructure. Figure 2e shows that $\mathrm{MnO}_{2}$ coats the external surface of the ACNF and also grows inside the hollow ACNF. Furthermore, the deposited $\mathrm{MnO}_{2}$ is actually a two-dimensional lamellar structure (Figure 2f), which could facilitate the adsorption of polysulfides. The elemental maps show that $\mathrm{MnO}_{2}$ is homogeneously deposited and distributed throughout the ACNF (Figure 2h). In addition, the ACNF@ $\mathrm{MnO}_{2}$ entangles well with CNT (Figure 2g). CNT provide a highly conductive, mechanically robust structure 
that enables efficient sulfur utilization. Figure $2 \mathrm{i}-\mathrm{k}$ shows that the CNT/ACNF@ $\mathrm{MnO}_{2}$ composite is approximately $70 \mu \mathrm{m}$ thick and exhibits excellent flexibility; it can be readily rolled and folded without cracks. In contrast, the ACNF@ $\mathrm{MnO}_{2}$ without CNT is very brittle and fractures easily under a small bending angle (Figure S3). The flexibility and mechanical robustness indicate its potential application for flexible energy storage devices.

The X-ray photoelectron spectroscopy (XPS) survey spectrum (Figure 3a) confirms the presence of $\mathrm{Mn}, \mathrm{C}$, and $\mathrm{O}$ elements in the CNT/ACNF@ $\mathrm{MnO}_{2}$ paper. The high-resolution Mn 2p spectrum (Figure 3b) shows two peaks located at $642.2 \mathrm{eV}$ $\left(\mathrm{Mn} 2 \mathrm{p}_{3 / 2}\right)$ and $653.8 \mathrm{eV}\left(\mathrm{Mn} 2 \mathrm{p}_{1 / 2}\right)$, with a spin orbit coupling separation of $11.6 \mathrm{eV}$, which is consistent with the previous reports on $\mathrm{MnO}_{2}$ [35]. The $4.8 \mathrm{eV}$ peak separation for Mn 3s and the calculated Mn valence of +3.6 further confirm that $\mathrm{MnO}_{2}$ is the dominant constituent (Figure S4) [36]. The presence of pure $\mathrm{MnO}_{2}$ is further verified by Raman spectroscopy (Figure S5) and X-ray diffraction (XRD) analyses (Figure 3c), which show that the birnessite-type $\mathrm{MnO}_{2}$ (JCPDS 42-1317) is formed after immersing carbon into $\mathrm{KMnO}_{4}$ solution at an elevated temperature. The weak, broad peaks indicate poor crystallinity, which is in accordance with the previous reports on $\mathrm{MnO}_{2}$ nanosheets prepared by reducing $\mathrm{KMnO}_{4}$ with carbon [37, 38]. $\mathrm{MnO}_{2}$ nanosheets in the birnessite phase help constrain the polysulfides within the hollow carbon fibers, and promote a fast redox reaction kinetics [39]. However, too much $\mathrm{MnO}_{2}$ in the cathode would compromise the overall energy density since $\mathrm{MnO}_{2}$ suffers from low conductivity and contributes negligibly to the capacity of Li-S 
batteries [40]. Therefore, we limited the reaction time to control the amount of as-grown $\mathrm{MnO}_{2}$. Thermogravimetric analysis (TGA) reveals that the $\mathrm{MnO}_{2}$ content in the composite is approximately $9.7 \mathrm{wt} \%$ (Figure 3d).

To demonstrate the advantages of $\mathrm{MnO}_{2}$ in absorbing polysulfides, we compared the cycle and rate performances of the Li/dissolved polysulfide cells containing a CNT/ACNF@ $\mathrm{MnO}_{2}$ host with those employing a CNT/ACNF host. It's worth noting that the CNT/ACNF@ $\mathrm{MnO}_{2}$ host contributes negligibly to the capacity in the voltage range of $1.8-2.8 \mathrm{~V}$ (Figure S6). As shown in Figure 4a, the CNT/ACNF@ $\mathrm{MnO}_{2}$ electrodes with a sulfur loading of $2.4 \mathrm{mg} \mathrm{cm}^{-2}$ deliver an initial capacity of $1022 \mathrm{~mA}$ $\mathrm{h} \mathrm{g}^{-1}$ at $0.2 \mathrm{C}$ rate and maintain a stable cyclability of $927 \mathrm{~mA} \mathrm{~h} \mathrm{~g}^{-1}$ after 100 cycles, with nearly $100 \%$ Coulombic efficiency. In contrast, the capacity of the CNT/ACNF electrode declines rapidly and only retains a capacity of $545 \mathrm{~mA} \mathrm{~h} \mathrm{~g}^{-1}$ after 100 cycles, even though the initial capacity is almost the same as that of CNT/ACNF@ $\mathrm{MnO}_{2}$. Furthermore, the electrode with $\mathrm{MnO}_{2}$ exhibits higher capacity for all $\mathrm{C}$ rates $(0.2 \mathrm{C}$ and $2 \mathrm{C}$ rates). As shown in Figure $4 \mathrm{~b}$, the CNT/ACNF@ $\mathrm{MnO}_{2}$ electrode exhibits excellent rate capability and high capacities of 1045, 1000, 955, 911, 878, and 773 $\mathrm{mAh} \mathrm{g}^{-1}$ at, respectively, $0.2 \mathrm{C}, 0.3 \mathrm{C}, 0.5 \mathrm{C}, 0.8 \mathrm{C}, 1 \mathrm{C}$, and $2 \mathrm{C}$ rates. More importantly, the capacity recovers to $\sim 915 \mathrm{mAh}^{-1}$ when the rate returns to $0.5 \mathrm{C}$ rate, corresponding to an areal capacity of $313 \mathrm{mAh} \mathrm{cm}^{-3}$, which is comparable to or higher than those reported previously [29, 41]. The significant enhancement in capacity and rate capability can be attributed to the effective localization of polysulfides by $\mathrm{MnO}_{2}$, which was further verified by visual observation (Figure S7). 
CNT in the CNT/ACNF@ $\mathrm{MnO}_{2}$ hybrid electrode also play a key role in improving the performances. The ACNF@ $\mathrm{MnO}_{2}$ electrode without CNT suffers from poor rate capability due to slow electron and ion transport (Figure S8).

Figure $4 \mathrm{c}$ shows the representative charge and discharge voltage profiles of cells with the CNT/ACNF@ $\mathrm{MnO}_{2}$ electrodes. The curves all display clear voltage plateau for the charge and discharge processes that are consistent with the typical cyclic voltammogram (CV) of Li-S cells (Figure S9) [42, 43]. The discharge plateaus correspond to the reduction of elemental sulfur to high-order polysulfides and then to $\mathrm{Li}_{2} \mathrm{~S}_{2} \mathrm{Li}_{2} \mathrm{~S}_{2}$, while the charge plateaus represent the reverse process (Figure S10) [44]. In addition, these cells show low polarization. For example, the cell displays a long, flat discharge plateau at $0.2 \mathrm{C}$ rate with a voltage gap of only $0.18 \mathrm{~V}$. Even at a high rate of $2 \mathrm{C}$, the voltage gap is no more than $0.6 \mathrm{~V}$, and the discharge plateau is still flat and remains above 1.9 V. These values are among the best reported results for Li-S batteries [45]. CV analyses at various scan rates were carried out to determine the lithium-ion diffusion coefficient. As plotted in Figure 4d and Figure S11, the linear relationship between Ip and $v^{0.5}$ indicate a diffusion-controlled process. The diffusion coefficient is calculated to be $D_{L i}{ }^{+}$(A, cathodic peak at $\left.2.3 \mathrm{~V}\right)=4.81 * 10^{-8} \mathrm{~cm}^{2} \mathrm{~s}^{-1}$, $D_{L i}{ }^{+}(\mathrm{C} 1$, cathodic peak at $2.0 \mathrm{~V})=6.42 * 10^{-8} \mathrm{~cm}^{2} \mathrm{~s}^{-1}$, and $D_{L i}{ }^{+}(\mathrm{C} 2$, cathodic peak at $2.35 \mathrm{~V})=7.41 * 10^{-9} \mathrm{~cm}^{2} \mathrm{~s}^{-1}$. The average $D_{L i}{ }^{+}$values for the cells with $\mathrm{MnO}_{2}$ are similar to those employing a regular host electrode, suggesting that the $\mathrm{MnO}_{2}$ does not affect the diffusion of lithium ions [46, 47]. Meanwhile, the presence of trace amount of $\mathrm{MnO}_{2}$ does not significantly increase the host electrode resistance since the 
baseline charge-transfer resistance $\left(\mathrm{R}_{\mathrm{ct}}\right)$ of the two fresh cells are almost the same (Figure $\mathrm{S} 12$ ). The $\mathrm{R}_{\mathrm{ct}}$ of the cell with $\mathrm{MnO}_{2}$ decreases after cycling, reflecting the redistribution of the active material on $\mathrm{MnO}_{2}$ and the carbon matrix. In contrast, the $\mathrm{R}_{\mathrm{ct}}$ of the cell without $\mathrm{MnO}_{2}$ increases significantly. This may be ascribed to the severe shuttle effect and the formation of a thick, insulating passivation layer on the Li anode [48]. The CNT/ACNF@ $\mathrm{MnO}_{2}$ host electrode also possesses excellent cycle stability during long-term cycling at $0.5 \mathrm{C}$ rate. As shown in Figure $4 \mathrm{e}$, the reversible capacity remains stable and eventually stabilizes at $618 \mathrm{mAh}^{-1}$ after 300 cycles, with an average capacity loss of $0.11 \%$ per cycle. The Coulombic efficiency is approximately $98 \%$ after 300 cycles, indicating that most polysulfides are trapped in the cathode side by $\mathrm{MnO}_{2}$.

To further explore the feasibility of the composite host for high sulfur loading, we prepared thicker electrodes by increasing the thickness of the filter-fabricated paper electrode. In this way, the sulfur loading could be further increased from 2.4 to 4.8 and even to $7.2 \mathrm{mg} \mathrm{cm}^{-2}$ as the thickness of host electrode increases. Figure $\mathbf{5 a}$ and b show the galvanostatic charge/discharge curves of the CNT/ACNF@ $\mathrm{MnO}_{2}$ electrode with sulfur loadings of 4.8 and $7.2 \mathrm{mg} \mathrm{cm}^{-2}$ at $0.2-2 \mathrm{C}$ rates. The two thick electrodes with high sulfur loadings display well-defined discharge/charge plateaus and low overpotential, suggesting good conductivity and full electrolyte wetting. The higher voltage gaps of the thicker electrode ( $\mathrm{S}$ loading: $7.2 \mathrm{mg} \mathrm{cm}^{-2}$ ) are ascribed to the increased concentration polarization of polysulfides in the cathode. These cells also exhibit high sulfur utilization with good cyclability at various rates. As shown in 
Figure $5 \mathrm{c}$, the electrode with $4.8 \mathrm{mg} \mathrm{cm}^{-2}$ sulfur delivers high capacities of 826,740 , and $627 \mathrm{mAh} \mathrm{g}^{-1}$, respectively, at $0.2 \mathrm{C}, 0.5 \mathrm{C}$, and $1 \mathrm{C}$ rates. Even with a high loading of $7.2 \mathrm{mg} \mathrm{cm}^{-2}$, the cell displays reversible capacities of as high as 765, 648, and 483 mAh g ${ }^{-1}$ at, respectively, $2.4,6$, and $12 \mathrm{~mA} \mathrm{~cm}^{-2}$, corresponding to areal capacities of 5.5, 4.6 and $3.5 \mathrm{mAh} \mathrm{cm}^{-2}$. Considering the thickness of the electrode, the calculated volumetric capacity at $2.4 \mathrm{~mA} \mathrm{~cm}^{-2}$ is around $262 \mathrm{mAh} \mathrm{cm}^{-3}$.

The thick electrodes with high sulfur loading also show good capacity retention (Figure 5d). At $0.5 \mathrm{C}$ rate, the electrodes with sulfur loadings of 4.8 and $7.2 \mathrm{mg} \mathrm{cm}^{-2}$ retain $87 \%$ and $76 \%$ of their original capacity after 100 cycles. These results are comparable to or better than those with similar sulfur loadings [7, 49-51]. The integrated design of the CNT/ACNF@ $\mathrm{MnO}_{2}$ electrode offers excellent electrode conductivity and space to accommodate polysulfides and efficiently traps the polysulfides within the cathode.

This hypothesis is also supported by the postmortem studies of the surface morphology of the cycled Li-metal anode. Figure 6a-e shows the fresh $\mathrm{Li}$ foil and cycled $\mathrm{Li}$ foil disassembled from cells employing the CNT/ACNF and CNT/ACNF@ $\mathrm{MnO}_{2}$ electrodes. Compared to the fresh Li foil (Figure 6a), the cycled Li from a cell employing a CNT/ACNF electrode (Figure 6b and c) exhibits a rough surface with lots of aggregated particles, which is caused by a severe corrosion of lithium metal by the polysulfides during extended cycling. In contrast, the cycled Li from cells employing the CNT/ACNF@ $\mathrm{MnO}_{2}$ exhibits a relatively smooth and dense surface (Figure 6d and e), implying that the polysulfides are effectively immobilized 
by $\mathrm{MnO}_{2}$. XRD analysis of the cycled Li foils (Figure 6f) indicates that fewer sulfur-related species are present on the foils cycled in cells with $\mathrm{MnO}_{2}$ than that in cells without $\mathrm{MnO}_{2}$, further confirming the reduced polysulfide shuttle in the presence of $\mathrm{MnO}_{2}$. Liquid polysulfides can easily diffuse into the anode and severely corrode the Li-metal anode during repeated cycling. However, trace amounts of polysulfides that diffuse into the anode side can help form a protective layer on the Li surface that alleviates Li corrosion and minimizes electrolyte decomposition [33]. To evaluate the effect of Li protection more directly, we assembled two cycled Li foils collected from the cells with $\mathrm{MnO}_{2}$ into a symmetrical coin cell (Figure 6g). For a comparison, a symmetrical cell with cycled $\mathrm{Li}$ foils from cells without $\mathrm{MnO}_{2}$ was also tested. Figure 6h illustrates the charge/discharge voltage profiles of the Li symmetric cells at $1 \mathrm{~mA}$ $\mathrm{cm}^{-2}$, which show the effect of the protection layer. The capacity is $3 \mathrm{mAh} \mathrm{cm}^{-2}$ for both charge and discharge. The symmetric cell with the cycled $\mathrm{Li}$ from a $\mathrm{MnO}_{2}$-containing cell displays a low and stable overpotential for $400 \mathrm{~h}$, which is ascribed to Li metal anode surface protection by the stable and uniform passivation film and the consequent suppressed electrolyte consumption [52]. In contrast, the cycled Li foils from cells without $\mathrm{MnO}_{2}$ are more porous and have a much larger surface area, which could greatly facilitate the soaking of electrolyte. The voltage hysteresis increases and eventually transforms into random oscillations as the electrolyte continuously corrodes the lithium metal.

\section{Conclusion}

In summary, we have demonstrated the effectiveness of an integrally-designed 
CNT/ACNF@ $\mathrm{MnO}_{2}$ host for lithium polysulfide cathodes. In this advanced design, hollow ACNFs serve as a reservoir for dissolved polysulfides and enable high sulfur loading, while CNTs act as a conductive network to enhance sulfur utilization and mechanical stability for the highly-flexible electrode. $\mathrm{MnO}_{2}$ is easily grown onto the CNT/ACNF scaffold and it chemically binds with polysulfides to effectively suppress them from diffusing out of the cathode. This advanced design enables high sulfur loadings from 2.4 to $7.2 \mathrm{mg} \mathrm{cm}{ }^{-2}$ with high rate capability, low polarization, and superior cycling performance at high current densities. Additionally, we reveal that trace amounts of lithium polysulfides diffused out of the cathode act as an electrolyte additive to protect the lithium-metal anode and thus efficiently prevent further Li-metal corrosion and electrolyte depletion. Our results show that the integrated electrode design holds great promise in developing flexible and high energy density Li-S batteries.

\section{Appendix A: Supplementary material}

Supplementary data associated with this article can be found in the online version.

\section{Acknowledgements}

This work was funded in part by the Advanced Research Projects Agency-Energy (ARPA-E), U.S. Department of Energy, under Award Number DE-AR0000377 and Welch Foundation grant F-1254. The authors also thank Dr. Shaofei Wang for helpful discussion and Craig Milroy for assistance with the XPS data. 


\section{References}

[1] S. Chu and A. Majumdar, Nature 488 (2012) 294-303.

[2] Y. X. Yin, S. Xin, Y. G. Guo and L. J. Wan, Angew. Chem. Int. Ed. 52 (2013) 13186-13200.

[3] A. Manthiram, Y. Fu and Y. S. Su, Acc. Chem. Res. 46 (2013) 1125-1134.

[4] Y. Yang, G. Zheng and Y. Cui, Chem. Soc. Rev. 42 (2013) 3018-3032.

[5] F. Jin, S. Xiao, L. Lu and Y. Wang, Nano Lett. 16 (2016) 440-447.

[6] J. Song, Z. Yu, M. L. Gordin and D. Wang, Nano Lett. (2016) DOI: 10.1021/acs.nanolett.5b03217.

[7] L. Sun, M. Li, Y. Jiang, W. Kong, K. Jiang, J. Wang and S. Fan, Nano Lett. 14 (2014) 4044-4049.

[8] L. Sun, D. Wang, Y. Luo, K. Wang, W. Kong, Y. Wu, L. Zhang, K. Jiang, Q. Li, Y. Zhang, J. Wang and S. Fan, ACS Nano (2015) DOI: 10.1021/acsnano.5b06675.

[9] X. Fang, W. Weng, J. Ren and H. Peng, Adv. Mater. 28 (2016) 491-496.

[10] Y. H. Xu, Y. Wen, Y. J. Zhu, K. Gaskell, K. A. Cychosz, B. Eichhorn, K. Xu and C. S. Wang, Adv. Funct. Mater. 25 (2015) 4312-4320.

[11] S. Rehman, X. Gu, K. Khan, N. Mahmood, W. Yang, X. Huang, S. Guo and Y. Hou, Adv. Energy Mater. (2016) DOI: 10.1002/aenm.201502518.

[12] Y. S. Su and A. Manthiram, Nat. Commun. 3 (2012) 1166.

[13] J. Y. Hwang, H. M. Kim, S.-K. Lee, J.-H. Lee, A. Abouimrane, M. A. Khaleel, I. Belharouak, A. Manthiram and Y.-K. Sun, Adv. Energy Mater. 6 (2016). 
[14] H. S. Kang and Y. K. Sun, Adv. Funct. Mater. (2015) DOI:

10.1002/adfm.201504262.

[15] F. Wu, Y. Ye, R. Chen, J. Qian, T. Zhao, L. Li and W. Li, Nano Lett. 15 (2015) 7431-7439.

[16] G. M. Zhou, Y. B. Zhao, C. X. Zu and A. Manthiram, Nano Energy 12 (2015) 240-249.

[17] X. Q. Niu, X. L. Wang, D. Xie, D. H. Wang, Y. D. Zhang, Y. Li, T. Yu and J.

P. Tu, ACS Appl. Mater. Interfaces 7 (2015) 16715-16722.

[18] Z. Xiao, Z. Yang, L. Wang, H. Nie, M. Zhong, Q. Lai, X. Xu, L. Zhang and S. Huang, Adv. Mater. 27 (2015) 2891-2898.

[19] J. Jiang, J. Zhu, W. Ai, X. Wang, Y. Wang, C. Zou, W. Huang and T. Yu, Nat. Commun. 6 (2015) 8622.

[20] Pang, D. Kundu, M. Cuisinier and L. F. Nazar, Nat. Commun. 5 (2014) 4759.

[21] Z. Yuan, H. J. Peng, T. Z. Hou, J. Q. Huang, C. M. Chen, D. W. Wang, X. B. Cheng, F. Wei and Q. Zhang, Nano Lett. 16 (2016) 519-527.

[22] Yu, J. Ma, H. Song, A. Wang, F. Tian, Y. Wang, H. Qiu and R. Wang, Energy Environ. Sci. 9 (2016) 1495-1503.

[23] Q. Fan, W. Liu, Z. Weng, Y. Sun and H. Wang, J. Am. Chem. Soc. 137 (2015) 12946-12953.

[24] X. Tao, J. Wang, Z. Ying, Q. Cai, G. Zheng, Y. Gan, H. Huang, Y. Xia, C. Liang, W. Zhang and Y. Cui, Nano Lett. 14 (2014) 5288-5294. 
[25] H. J. Peng, T. Z. Hou, Q. Zhang, J. Q. Huang, X. B. Cheng, M. Q. Guo, Z. Yuan, L. Y. He and F. Wei, Adv. Mater. Interfaces 1 (2014).

[26] X. Pu, G. Yang and C. Yu, Adv. Mater. 26 (2014) 7456-7461.

[27] Y. Yang, G. Y. Zheng and Y. Cui, Energy Environ. Sci. 6 (2013) 1552-1558.

[28] K. Han, J. Shen, S. Hao, H. Ye, C. Wolverton, M. C. Kung and H. H. Kung, ChemSusChem 7 (2014) 2545-2553.

[29] L. Qie and A. Manthiram, Adv. Mater. 27 (2015) 1694-1700.

[30] L. Qie, C. Zu and A. Manthiram, Adv. Energy Mater. (2016) DOI: 10.1002/aenm.201502459.

[31] A. E. Fischer, M. P. Saunders, K. A. Pettigrew, D. R. Rolison and J. W. Long, J. Electrochem. Soc. 155 (2008) A246-A252.

[32] A. E. Fischer, K. A. Pettigrew, D. R. Rolison, R. M. Stroud and J. W. Long, Nano Lett. 7 (2007) 281-286.

[33] W. Li, H. Yao, K. Yan, G. Zheng, Z. Liang, Y. M. Chiang and Y. Cui, Nat. Commun. 6 (2015) 7436.

[34] M. Agostini, B. Scrosati and J. Hassoun, Adv. Energy Mater. 5 (2015).

[35] H. Xu, X. Hu, H. Yang, Y. Sun, C. Hu and Y. Huang, Adv. Energy Mater. 5 (2015).

[36] M. Chigane and M. Ishikawa, J. Electrochem. Soc. 147 (2000) 2246-2251.

[37] X. Zhu, P. Zhang, S. Xu, X. Yan and Q. Xue, ACS Appl. Mater. Interfaces 6 (2014) 11665-11674. 
[38] Y. Zhou, C. Zhou, Q. Li, C. Yan, B. Han, K. Xia, Q. Gao and J. Wu, Adv. Mater. 27 (2015) 3774-3781.

[39] X. Liang, C. Hart, Q. Pang, A. Garsuch, T. Weiss and L. F. Nazar, Nat. Commun. 6 (2015) 5682.

[40] S. Wang, Z. Yang, H. Zhang, H. Tan, J. Yu and J. Wu, Electrochim. Acta 106 (2013) 307-311.

[41] X. B. Cheng, J. Q. Huang, Q. Zhang, H. J. Peng, M. Q. Zhao and F. Wei, Nano Energy 4 (2014) 65-72.

[42] J. Liu, W. Li, L. Duan, X. Li, L. Ji, Z. Geng, K. Huang, L. Lu, L. Zhou, Z. Liu, W. Chen, L. Liu, S. Feng and Y. Zhang, Nano Lett. 15 (2015) 5137-5142.

[43] L. Ma, H. L. Zhuang, S. Wei, K. E. Hendrickson, M. S. Kim, G. Cohn, R. G. Hennig and L. A. Archer, ACS Nano, (2015) DOI: 10.1021/acsnano.5b06373.

[44] C. X. Zu and A. Manthiram, Adv. Energy Mater. 4 (2014).

[45] S. H. Chung, P. Han, R. Singhal, V. Kalra and A. Manthiram, Adv. Energy Mater. 5 (2015).

[46] J. Q. Huang, T. Z. Zhuang, Q. Zhang, H. J. Peng, C. M. Chen and F. Wei, ACS Nano 9 (2015) 3002-3011.

[47] H. Kim, J. Lee, H. Ahn, O. Kim and M. J. Park, Nat. Commun. 6 (2015) 7278.

[48] F. Wu, J. T. Lee, N. Nitta, H. Kim, O. Borodin and G. Yushin, Adv. Mater. 27 (2015) 101-108.

[49] Z. Yuan, H. J. Peng, J. Q. Huang, X. Y. Liu, D. W. Wang, X. B. Cheng and Q. Zhang, Adv. Funct. Mater. 24 (2014) 6105-6112. 
[50] Z. Zhang, H. K. Jing, S. Liu, G. R. Li and X. P. Gao, J. Mater. Chem. A 3 (2015) 6827-6834.

[51] K. Jin, X. Zhou, L. Zhang, X. Xin, G. Wang and Z. Liu, J. Phys. Chem. C 117 (2013) 21112-21119.

[52] W. Luo, L. Zhou, K. Fu, Z. Yang, J. Wan, M. Manno, Y. Yao, H. Zhu, B. Yang, L. Hu, Nano Lett. 15 (2015) 6149-6154. 


\section{Figure Captions:}

Figure 1. Schematic illustration of the flexible CNT/ACNF@ $\mathrm{MnO}_{2}$ electrode synthesis and the advantages of the $\mathrm{CNT} / \mathrm{ACNF} @ \mathrm{MnO}_{2}$ host over CNT/ACNF in suppressing the shuttle effect and protecting the Li-metal anode.

Figure 2. (a, b) SEM images of the CNT/ACNF paper. (c, d) SEM, (d-f) TEM, (h) elemental mapping, (i) cross-sectional view, and (j, k) digital images of the CNT/ACNF@ $\mathrm{MnO}_{2}$ paper.

Figure 3. (a) Survey XPS and (c) high-resolution Mn 2p spectra of the CNT/ACNF@ $\mathrm{MnO}_{2}$ paper. c) XRD patterns of CNT/ACNF and CNT/ACNF@ $\mathrm{MnO}_{2}$ paper. (d) TGA curves of CNT/ACNF@ $\mathrm{MnO}_{2}$ in air with a heating rate of $10^{\circ} \mathrm{C} \mathrm{min}^{-1}$.

Figure 4. (a) Cycling performances and (b) rate capability of the Li/dissolved polysulfide cells with CNT/ACNF and CNT/ACNF@ $\mathrm{MnO}_{2}$ host electrodes. (c) Voltage profiles at various $\mathrm{C}$ rates, (d) $\mathrm{CV}$ curves at different scan rates, and (e) cycling performance at $0.5 \mathrm{C}$ rate over 300 cycles of the cells with the CNT/ACNF@ $\mathrm{MnO}_{2}$ electrodes. Here, the volumetric capacity is calculated based on the volume of the CNT/ACNF@ $\mathrm{MnO}_{2}$ host.

Figure 5. Electrochemical performance of cells employing CNT/ACNF@ $\mathrm{MnO}_{2}$ electrode with sulfur loadings of 4.8 and $7.2 \mathrm{mg} \mathrm{cm}^{-2}$ : voltage profiles of cells with sulfur loadings of (a) $4.8 \mathrm{mg} \mathrm{cm}^{-2}$ and (b) $7.2 \mathrm{mg} \mathrm{cm}^{-2}$ at various $\mathrm{C}$ rates, (c) rate capability, and (d) cycling performances at $0.5 \mathrm{C}$ rate. 
Figure 6. (a) SEM image of a fresh Li foil before cycling. SEM images of the cycled Li foils in the cells with (b, c) CNT/ACNF and (d, e) CNT/ACNF@ $\mathrm{MnO}_{2}$ composite electrode. (f) Comparison of the XRD patterns of the cycled $\mathrm{Li}$ foils with and without $\mathrm{MnO}_{2}$ in the cathode. (g) Schematic of the symmetrical cell design. (h) Comparison of the voltage profiles of the $\mathrm{Li}$ symmetric cells employing the cycled Li from disassembled cells with the two composite electrodes: the current density of the Li plating/stripping process was set at $1 \mathrm{~mA} \mathrm{~cm}^{-2}$ and each half-cycle lasted for $3 \mathrm{~h}$. 


\section{Figure 1}
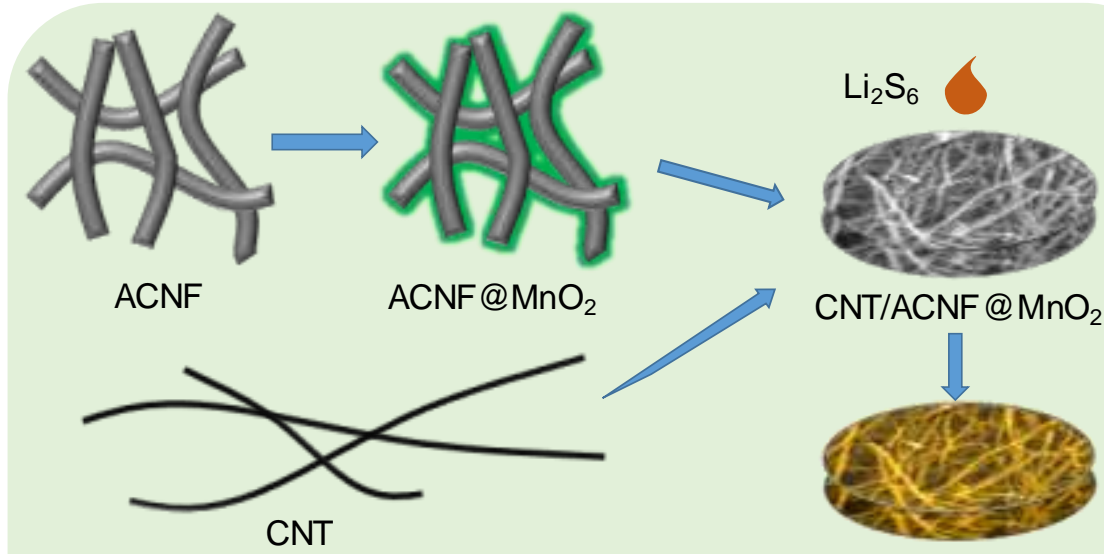

Li

CNT/ACNF-Li $2 \mathrm{~S}_{6}$

$\mathrm{CNT} / \mathrm{ACNF} @ \mathrm{MnO}_{2}-\mathrm{Li}_{2} \mathrm{~S}_{6}$

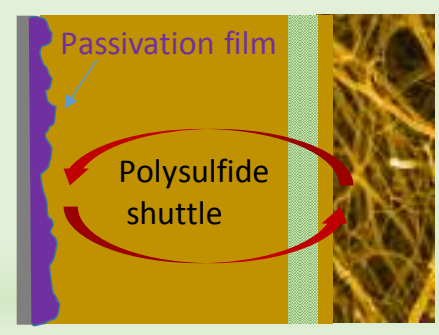

Separator

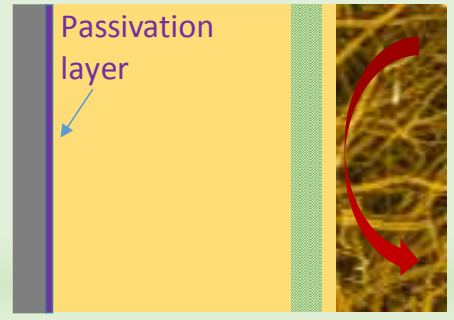

Separator 
Figure 2

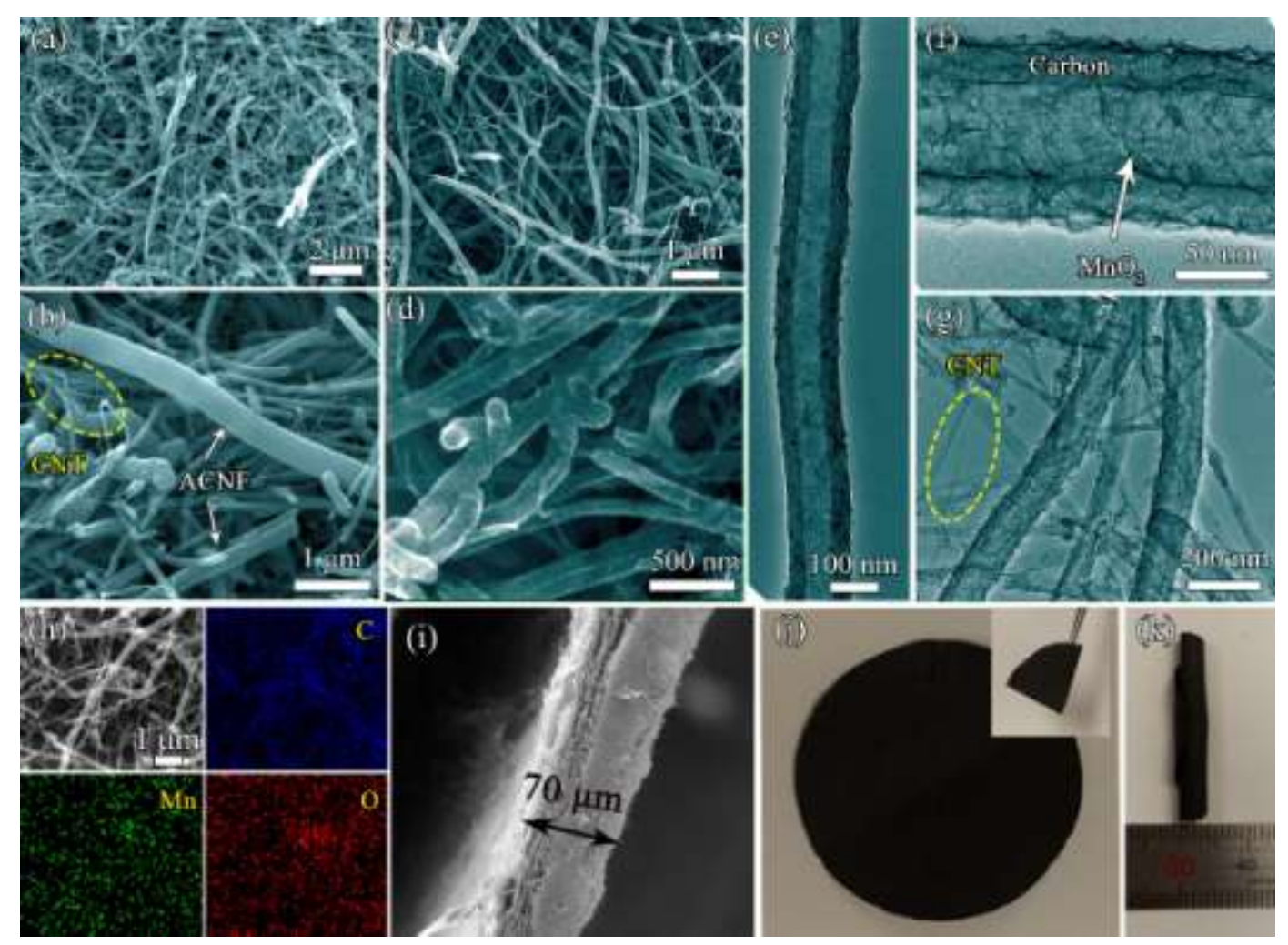




\section{Figure 3}
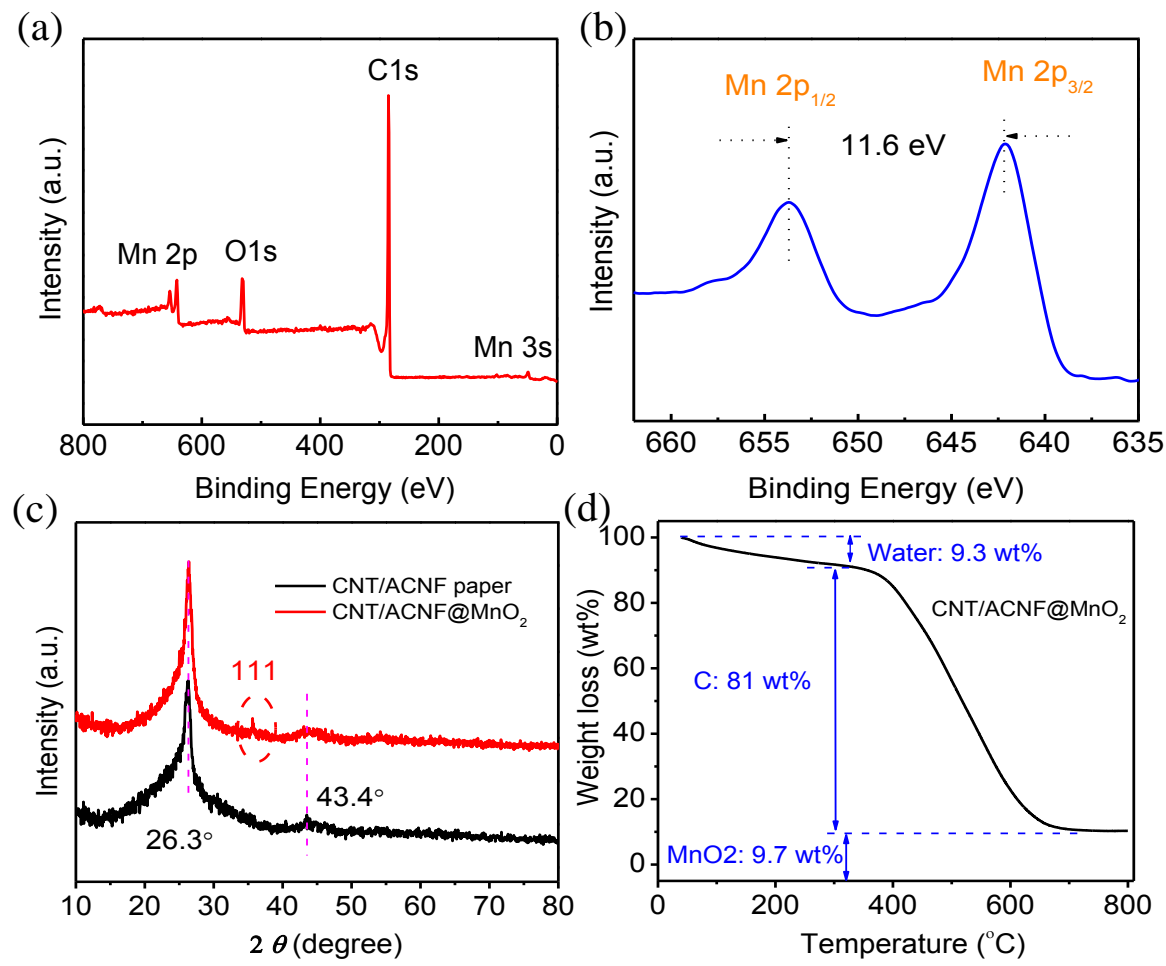


\section{Figure 4}

(a)

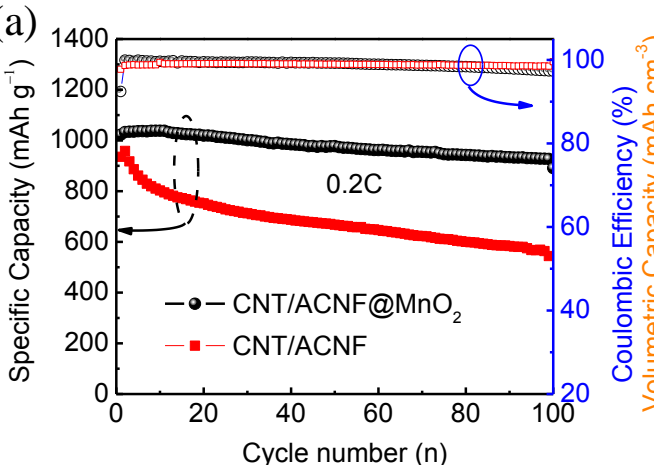

(c)

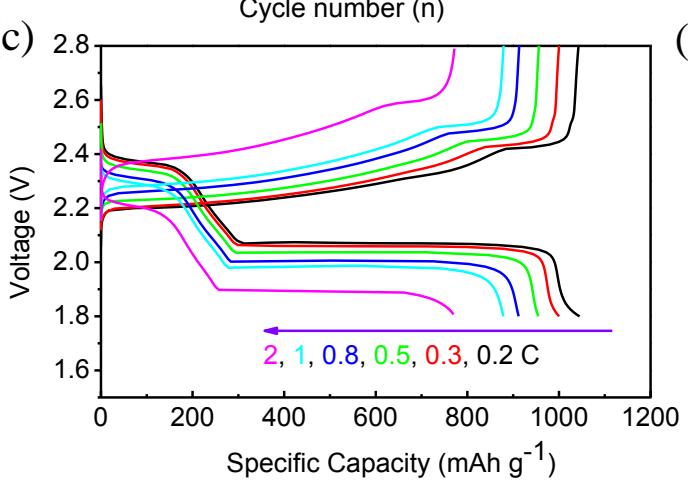

(b)

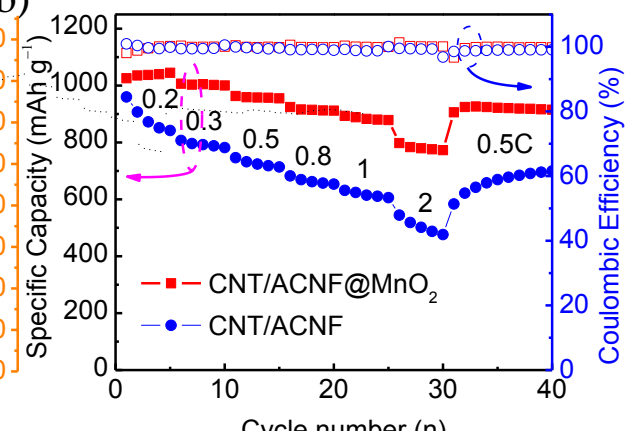

(d) Cycle number (n)

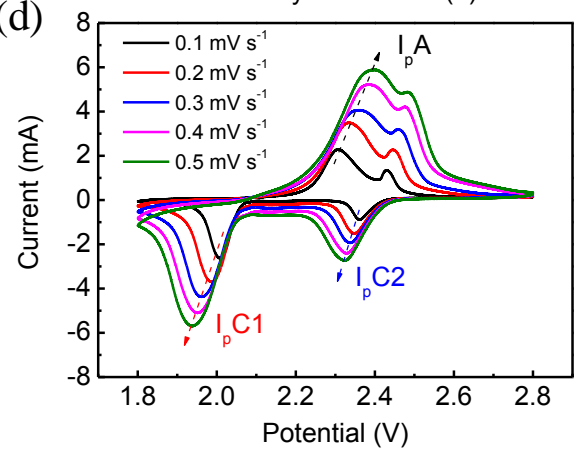

(e)

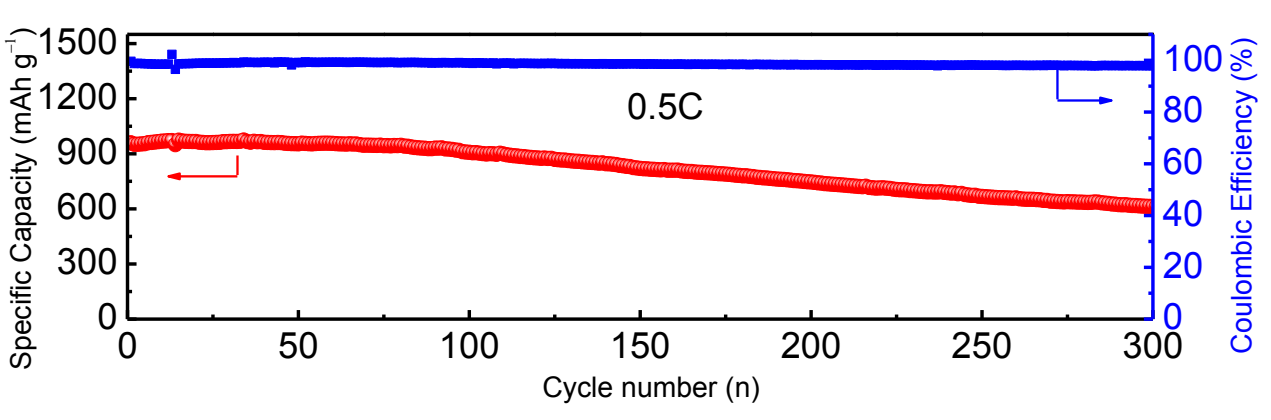




\section{Figure 5}
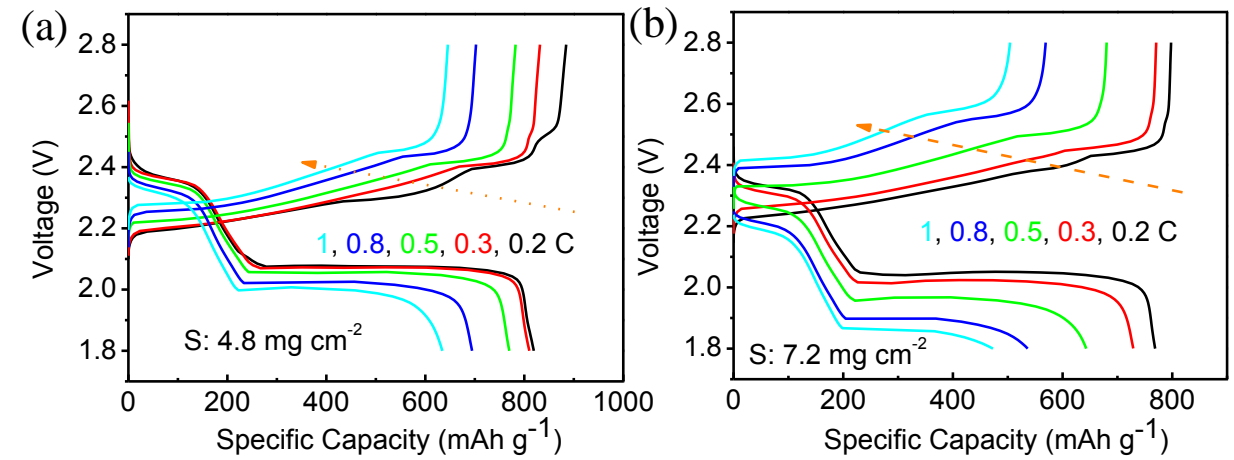

(c)

(d)
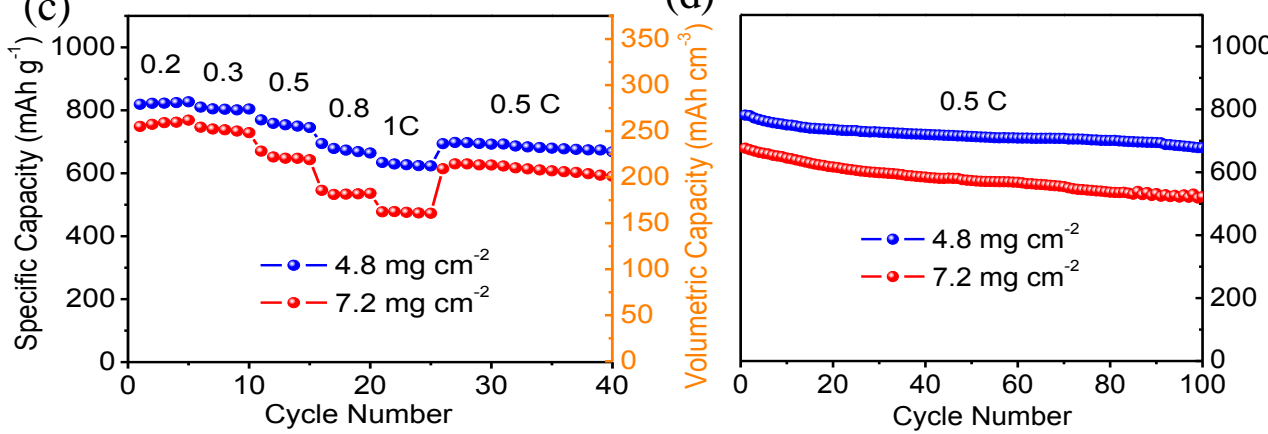


\section{Figure 6}

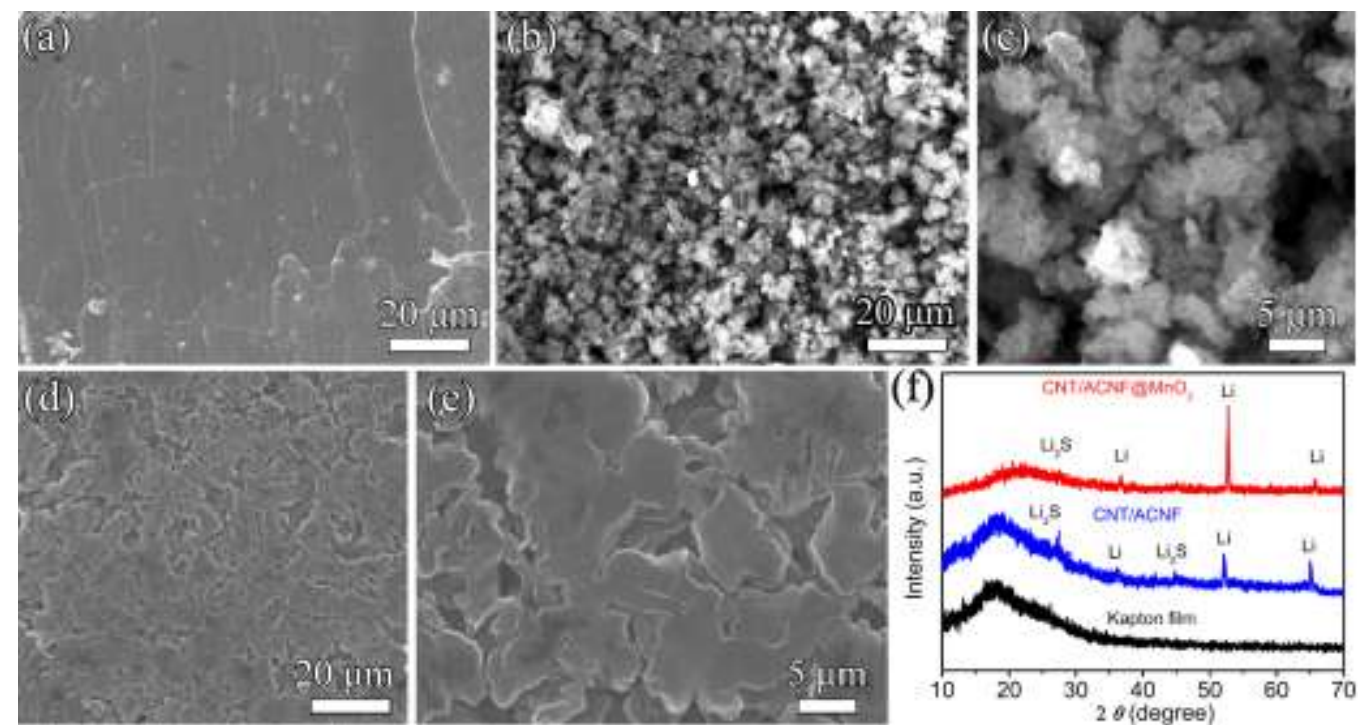

(g)

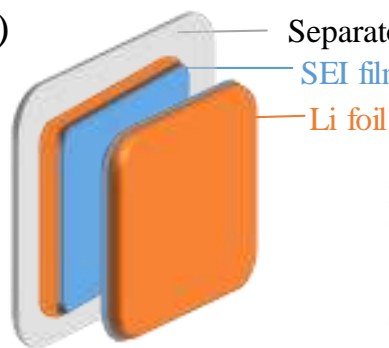

Li symmetric cell

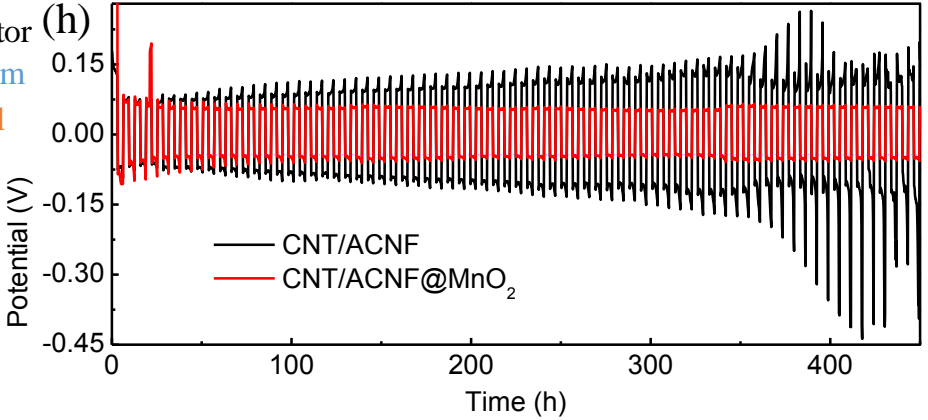

